\title{
DETERMINANTES E PREVISÃO DA TAXA DE CÂMBIO NOMINAL: UMA APLICAÇÃO DO MODELO DE PARIDADE DA TAXA DE JUROS ATRELADO AO MERCADO MONETÁRIO, 1999-2004 ${ }^{1}$
}

\author{
Francisco C. C. Cassuce ${ }^{2}$ \\ Leonardo Bornacki de Mattos ${ }^{3}$ \\ Antônio Carvalho Campos ${ }^{4}$
}

Resumo - Este trabalho procurou mostrar a influência de variáveis nominais na determinação da taxa de câmbio nominal, R \$/US\$. Para isso, utilizou-se o modelo da paridade da taxa de juros atrelado ao mercado monetário. Procurou-se, também, prever a taxa de câmbio R\$/US\$, até o mês de dezembro de 2005. Para que tais objetivos fossem alcançados, as equações do sistema foram obtidas pela Modelagem de Correção de Erros Vetorial (MCEV). Os resultados mostraram que as variáveis nominais são de suma importância para a determinação da taxa de câmbio e que o modelo de paridade da taxa de juros, atrelado ao mercado monetário, se confirma no caso brasileiro, no período de análise deste trabalho (jan./1999 a dez./2004). Esta conclusão se baseia no alto poder de previsão do modelo estruturado para o desenvolvimento do estudo. Com base nas previsões feitas, a taxa de câmbio apresenta leve tendência de queda até dezembro de 2005 , fechando por volta de $2,45 \mathrm{R}$ /US\$.

Palavras-chave: taxa de câmbio, previsão, Brasil.

\footnotetext{
Recebido em 14/07/2005. Aceito em 03/10/2005.

2 Doutorando em Economia Aplicada pela Universidade Federal de Viçosa-DER, Viçosa-MG. fcccassuce@yahoo.com.br.

3 Doutorando em Economia Aplicada pela Universidade Federal de Viçosa-DER, Viçosa-MG. Bolsista do CNPq. leobornacki@yahoo.com.br.

4 Professor Titular do Departamento de Economia Rural da Universidade Federal de Viçosa, Viçosa-MG. accampos@ufv.br
} 


\section{Introdução}

Este trabalho pretende determinar previsões para a taxa de câmbio nominal, visto que, a partir destas, serão tomadas decisões ligadas às informações sobre câmbio.

A taxa de câmbio é uma variável extremamente importante para a economia, por afetar variáveis reais e financeiras, como exportação, importação, entrada e saída de capitais, inflação, produção e emprego. Em janeiro de 1999, início do período de análise deste trabalho, houve mudança na política cambial, quando se abandonou o regime de bandas e adotou-se o de câmbio flutuante. O cenário envolvia uma revisão do acordo com o FMI, moratória decretada pelo governo do Estado de Minas Gerais, especulações sobre mudanças no BACEN e no Ministério da Fazenda, dentre outros acontecimentos, aliado à drástica queda na credibilidade e à disposição das instituições financeiras em manter posição comprada, que levaram à mudança na política cambial (BACEN, 1999). Como conseqüências dessa mudança, registraram-se quedas nas contratações de importação e exportação, embora a da primeira fosse bem superior. No lado financeiro, a situação foi semelhante. As incertezas a respeito do campo econômico e político, que minaram a credibilidade do governo, fizeram com que se registrassem fortes transferências ao exterior. Dentre as principais rubricas afetadas podem-se destacar Empréstimos a Residentes, Investimentos Diretos e Mercado de Capitais.

Já na segunda metade de 1999, o ambiente ficou mais estável e, apesar das desvalorizações cambiais, as saídas de capitais de curto prazo foram controladas. No segundo semestre de 2001, a balança comercial começou a esboçar reações e, em 2002, já se apresentou superavitária, acompanhada de estabilidade financeira e cambial. Segundo Barbosa (2004), no final do ano de 2002, diante das incertezas geradas pelo processo de eleição e da possibilidade de vitória do candidato de oposição (o atual presidente Luiz Inácio Lula da Silva), ocorreram fortes crises cambiais e especulativas que resultaram em desvalorizações bruscas da moeda brasileira e na saída de capitais. 
No ano de 2003, passado o processo eleitoral, observou-se recuperação do real diante do dólar. No mesmo ano, houve superávits consecutivos na balança comercial e déficits, embora com tendência de queda, em movimentos financeiros (BACEN, 2003a, BACEN, 2003b e BACEN, 2003c). O ano de 2004 foi marcado pela estabilidade cambial e pelos superávits na balança comercial, os quais permaneceram no primeiro trimestre de 2005, porém acompanhados de forte valorização do real em frente ao dólar.

Diante da importante influência da taxa de câmbio nominal nas decisões de importar e exportar e nas movimentações financeiras do país, no sentido de captar recursos, é interessante que se possa prever o comportamento futuro dessa variável e, dessa forma, fazer inferências sobre os demais indicadores por ela influenciados.

Na tentativa de estabelecer relações da taxa de câmbio nominal com os demais indicadores, foi utilizada a paridade descoberta da taxa de juros, atrelada à análise do mercado monetário. Gondim e Domingues (2003) mostraram que a evolução da taxa de câmbio, no período de janeiro de 1995 a março de 2003, seria mais bem explicada por modelos grafistas e por modelos de paridade da taxa de juros. Esses autores encontraram a influência desprezível do M1 e do PIB no comportamento da taxa de câmbio real. Takami e Leme (2003) concluíram que não há evidências empíricas sobre a ocorrência da paridade de taxa de juros, no período de agosto de 2001 a janeiro de 2003. Esses autores, ao citarem Miguel (1999) e Sachsida (1999), discorrem sobre a tentativa das autoridades monetárias em controlar a taxa de câmbio nominal e a taxa de juros doméstica, simultaneamente; a partir daí, sugeriram estudos que incorporassem a função de reação da política monetária ao aumento da taxa de câmbio nominal.

Holanda e Cavalcante (1997), ao estudarem a mobilidade de capitais internacionais no Brasil, no período de 1987 a 1996, confirmaram a hipótese de paridade coberta e rejeitaram a de paridade descoberta da taxa de juros, no que concerne ao estudo da mobilidade perfeita de capital. 
Maia e Ramalho (2003) enfatizaram que pesquisas a respeito da Paridade do Poder de Compra mostraram que mudanças monetárias e financeiras são responsáveis, na maior parte, pelas flutuações na taxa de câmbio nominal, o que foi corroborado por Rogoff (1996). Em seu estudo, Maia e Ramalho (2003) confirmaram o efeito ultrapassagem da taxa de câmbio nominal, R\$/US\$. Além disso, este estudo mostrou que, apesar de os choques reais terem maior influência na taxa de câmbio real e nominal, no curto prazo, cerca de $38 \%$ da taxa de câmbio nominal são determinados por variáveis nominais, o que mostra a importância dessas variáveis para a determinação do câmbio nominal. Os mesmos resultados, que relacionam taxas de câmbio real e nominal com choques reais e nominais, foram encontrados por Kannebley Júnior e Pazello (2003). Braga (2005) rejeitou a Paridade do Poder de Compra, no que tange à determinação da taxa de câmbio real, e concluiu que os principais determinantes dessa taxa são variáveis reais, como produtividade relativa ao exterior e passivo externo líquido.

Os trabalhos citados mostram a importância de variáveis reais e nominais para a determinação da taxa de câmbio nominal. Dessa forma, este trabalho pretende estabelecer relações entre taxa de câmbio nominal e variáveis reais e nominais, e, por meio dos modelos elaborados, realizar previsões do câmbio nominal até o mês de dezembro de 2005. A qualidade do ajustamento dessas previsões irá determinar se a escolha do modelo de paridade da taxa de juros, atrelado ao mercado monetário, mostrouse adequada.

\section{Referencial teórico}

2.1. Paridade dos juros, mercado monetário e taxa de câmbio

O desenvolvimento tecnológico e a globalização dos mercados internacionais aumentaram a movimentação e o número de investimentos feitos em ativos financeiros. Os investimentos em tais ativos levam em consideração as relações cambiais; dessa forma, a demanda de ativos 
financeiros por diversos países afeta a taxa de câmbio de equilíbrio do mercado. Assim, os rendimentos dos ativos são de suma importância para determinar os níveis de investimentos realizados em determinado país. Ao considerar duas moedas, o real e o dólar, admite-se que a taxa de câmbio é fundamental para determinar qual ativo, se em dólar ou se em real, é mais lucrativo, partindo do princípio que esta taxa seria a única capaz de converter rendimentos em real para dólar e vice-versa, o que possibilita, assim, uma análise comparativa.

Com isso, a determinação do rendimento de um depósito em dólares, medida em reais, é dada pela seguinte expressão (Krugman e Obstfeld, 2005):

$$
R_{R \$}=R_{U S \$}+\frac{\left(\Delta E^{e}\right)}{E},
$$

com $\Delta E^{e}=E_{R \$ / U S \$}^{e}-E_{R \$ / U S \$}$, em que $R_{R \$}$ é taxa de juros em real ou o rendimento esperado do depósito em reais; o lado direito da expressão (1) expressa o rendimento esperado do depósito em dólar, medido em reais, sendo $R_{U S \$}$ a taxa de juros americana, $E_{R \$ / U S \$}^{e}$, a taxa de câmbio esperada do real em frente ao dólar e $E_{R \$ / U S \$}$, a taxa de câmbio observada no período. O rendimento em dólares de um ativo, medido em reais, é dado pela taxa de juros americana mais a variação esperada na taxa de câmbio, R\$/US\$.

Dessa forma, as aplicações seriam feitas em ativos em dólar, caso o lado direito da expressão (1) fosse maior do que o lado esquerdo de (1), ou em reais, caso o lado esquerdo da expressão (1) fosse maior do que o lado direito de (1).

A tendência é que o rendimento dos depósitos em reais se iguale ao dos depósitos em dólares, medidos em reais. Essa igualdade é conhecida como paridade da taxa de juros, que é, até certo ponto, intuitiva. Admitindo 
que os rendimentos em reais superem os rendimentos em dólares, medidos em reais, os investidores preferirão manter seus depósitos em reais, o que elevará a demanda de depósitos em reais e reduzirá a demanda de depósitos em dólares. Isso fará com que o rendimento dos depósitos em reais caia e o dos depósitos em dólares se eleve, na medida em que maior demanda de depósitos em reais tende a apreciar o câmbio, chegando ao ponto em que os rendimentos sejam iguais e, nesse ponto, o mercado de câmbio esteja em equilíbrio, pois nenhum tipo de depósito terá excesso de demanda ou de oferta. Nesse sentido, a paridade da taxa de juros é essencial para que o mercado de câmbio esteja em equilíbrio.

A Figura 1 apresenta a união dos mercados monetário e de câmbio na determinação da taxa de câmbio de equilíbrio. A parte superior da Figura 1 mostra o equilíbrio no mercado de câmbio, em que o rendimento dos depósitos em dólar se iguala ao dos depósitos em reais, atendendo à condição de paridade da taxa de juros. O mercado de câmbio encontrase em equilíbrio, o que determina uma taxa de câmbio de equilíbrio.

A parte inferior da Figura 1 representa o mercado monetário brasileiro. A demanda de moeda é representada pela curva L, que depende da renda disponível $(\mathrm{Y})$ e da taxa de juros $\left(\mathrm{R}_{\mathrm{R}}\right)$. A oferta de moeda $\left(\mathrm{M}^{\mathrm{s}}\right)$ é determinada pelo governo. O equilíbrio entre demanda e oferta de moeda determina a taxa de juros de equilíbrio e o saldo real de moeda no Brasil.

À medida que ocorrerem mudanças na demanda ou na oferta de moeda, ocorrerão alterações na taxa de juros brasileira. Se prevalecesse a paridade da taxa de juros, a taxa de câmbio de equilíbrio sofreria alterações. 


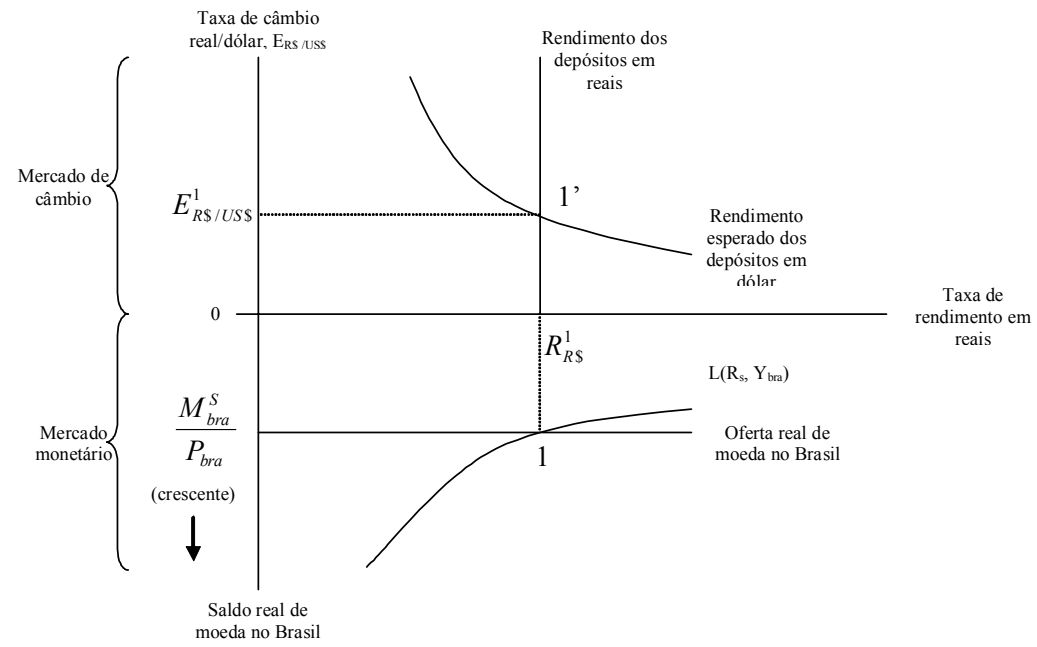

Fonte: Adaptado de Krugman e Obstefeld (2005).

Figura 1 - Equilíbrio simultâneo no mercado monetário e no mercado de câmbio.

Da mesma forma, mudanças na taxa de câmbio esperada deslocariam a curva de rendimentos esperados dos depósitos em dólar, em real, o que faria com que o mercado de câmbio estabelecesse nova taxa de câmbio de equilíbrio, assim como mudanças na taxa de juros americana.

\subsection{Modelo empírico}

Foram especificadas duas formas para determinar a taxa de câmbio de equilíbrio. A primeira leva em consideração o modelo citado e é representada pela equação (2): 


$$
E_{R S / U S S}=\alpha_{1} R_{R S}+\alpha_{2} R_{U S S}+\alpha_{3} E_{R S / U S S}^{e}+\alpha_{4} L+\alpha_{5} M^{S}+\alpha_{6} Y+\alpha_{7} I G P,
$$

em que IGP representa a variação nos preços, dada pelo índice de preços IGP-DI, com base em dezembro de 2004. As demais variáveis foram definidas anteriormente.

A segunda especificação para estimar a taxa de câmbio levou em consideração, além das variáveis já apresentadas na equação (3), as variações nos preços americanos, representados pelo Índice de Preços no Atacado (IPA) com base em dezembro de 2004, conforme equação (3).

$$
E_{R S / U S S}=\alpha_{1} R_{R S}+\alpha_{2} R_{U S S}+\alpha_{3} E_{R S / U S S}^{e}+\alpha_{4} L+\alpha_{5} M^{S}+\alpha_{6} Y+\alpha_{7} I G P_{B R A}+\alpha_{8} I P A_{E U A}
$$

A adição da variável IPA no mercado americano teve o intuito de captar os efeitos de possíveis variações no déficit público americano. Esse procedimento está embasado na teoria, citada por Blanchard (1999), de que maior déficit público será relacionado, positivamente, com elevação de preços, se o financiamento desse déficit for realizado por meio da expansão monetária ${ }^{5}$.

Para estimar tais relações, optou-se pela utilização de modelos VAR, ou seja, pela modelagem auto-regressiva e, por meio deste modelo, apresentarem-se os vetores de co-integração, que demonstram as relações de longo prazo entre as variáveis. Segundo Engle e Granger (1987), citados por Schmidt e Lima (2004), o VAR é representado na forma de um Modelo de Correção de Erros Vetorial.

Além disso, esses modelos foram utilizados nas previsões acerca da taxa de câmbio R $\$$ USS, por serem considerados bons previsores, levando em conta variáveis defasadas e incorporando, dessa forma, tendências de curto e longo prazos.

A elevação da base monetária americana, no período, pode ser confirmada pela análise dos dados coletados no site do Federal Reserve (FED). 
Os dados referentes a taxa de juros brasileira (SELIC), americana (PRIME), IGP-DI brasileiro e IPA americano, taxa de câmbio e taxa de câmbio esperada (câmbio no paralelo) foram obtidos no site do IPEA, enquanto os referentes a demanda de moeda (M1) e oferta de moeda (base monetária) foram extraídos do site da Fundação Getúlio Vargas e compreendem o período de janeiro de 1999 a dezembro de 2004.

\section{Discussão dos resultados}

À exceção das séries referentes à taxa de juros nacional (SELIC) e da demanda de moeda (M1), todas as outras variáveis apresentaram séries que foram estacionárias apenas na primeira diferença. As duas séries, citadas acima, foram estacionárias em nível e na primeira diferença. $\mathrm{O}$ próximo passo é determinar o número de defasagens que serão inseridas no modelo. Para isso, utilizaram-se os testes de Akaike (AIC), Schwartz (SBC) e Hannan-Quinn (HQ). No modelo sem o IPA americano, o teste AIC determinou seis defasagens contra uma do teste SBC e duas do teste HQ. Já no modelo que continha o IPA americano, a única variação foi a determinação de seis defasagens pelo teste HQ. Tomando a natureza do objeto de estudo e considerando o horizonte de tempo objetivado para realização das previsões deste trabalho, optou-se por estimar os modelos com duas defasagens, pois este foi o número de defasagens que apresentou melhores resultados de previsão, além de tratar de previsões para um horizonte de tempo muito próximo.

Determinado o número de defasagens, procurou-se estabelecer se as séries eram co-integradas e se havia presença de auto-correlação e de heterocedasticidade. Em ambos os modelos, as séries foram cointegradas $^{6}$ e livres da presença de auto-correlação serial e de heterocedasticidade. Os resultados desses testes e dos citados anteriormente encontram-se nas tabelas anexas.

Segundo Schmidt e Lima (2004), ao citarem Rahbek e Mosconi (1999), mesmo se existissem N séries não-estacionárias de mesma ordem e $\mathrm{M}$ séries estacionárias, $\mathrm{se} \mathrm{M}<\mathrm{N}$, os resultados dos testes de co-integração não se alterariam. 
Terminada a fase de especificação estatística dos modelos, as equações de co-integração são apresentadas em ambos os modelos e utilizadas para determinar as relações de longo prazo entre as variáveis explicativas e a taxa de câmbio.

A equação de co-integração, estimada para o modelo que não contém o IPA americano como variável explicativa, é apresentada na Tabela 1.

Tabela 1 - Equação de co-integração, estimada a partir de um modelo VAR para taxa de câmbio nominal, representado na forma de um modelo de correção de erros vetorial

\begin{tabular}{|c|c|c|c|c|c|c|c|}
\hline Câmbio & IGP-DI & $\begin{array}{l}\text { Demanda } \\
\text { de moeda }\end{array}$ & $\begin{array}{l}\text { Oferta de } \\
\text { moeda }\end{array}$ & $\begin{array}{l}\text { Taxa de } \\
\text { câmbio } \\
\text { esperado }\end{array}$ & $\begin{array}{l}\text { Taxa de } \\
\text { juros } \\
\text { americana }\end{array}$ & Renda & $\begin{array}{c}\text { Taxa de } \\
\text { juros } \\
\text { nacional }\end{array}$ \\
\hline 1 & $\begin{array}{c}-0,022^{*} \\
(0,0065) \\
{[3,3973]}\end{array}$ & $\begin{array}{c}-3,24 \mathrm{E}-05^{*} \\
(4,0 \mathrm{E}-06) \\
{[7,4803]}\end{array}$ & $\begin{array}{c}5,2 \mathrm{E}-05^{*} \\
(9,0 \mathrm{E}-06) \\
{[-6,0377]}\end{array}$ & $\begin{array}{c}1,9^{*} \\
(0,0859) \\
{[-22,1028]}\end{array}$ & $\begin{array}{c}0,045^{*} \\
(0,0058) \\
{[-7,6948]}\end{array}$ & $\begin{array}{c}-3,38 \mathrm{E}-05^{* *} \\
(1,4 \mathrm{E}-05) \\
{[2,3754]}\end{array}$ & $\begin{array}{c}-0,062^{*} \\
(0,0038) \\
{[16,3641]}\end{array}$ \\
\hline
\end{tabular}

Fonte: dados do trabalho.

OBS: Os valores entre parênteses correspondem ao desvio-padrão e os valores em colchete, ao t-valor.

*- significativo a $1 \%$.

$* *$ - significativo a $5 \%$.

Como esperado, o sinal referente às variáveis significativas estatisticamente foram coerentes com a teoria. A taxa de juros brasileira influenciou, negativamente, a taxa de câmbio na ordem de 0,062 , ou seja, um aumento de um ponto percentual na taxa de juros nacional reduziu a taxa de câmbio em 0,062 unidades. Essa redução na taxa de câmbio deveu-se ao aumento na demanda de títulos denominados em reais, que provoca a valorização da moeda brasileira. O mesmo pode ser dito do IGP-DI. Aumentos nesse índice de preços reduziram a oferta real de moeda e elevaram a taxa de juros, causando o mesmo efeito anterior sobre a taxa de câmbio. 
A taxa de câmbio esperada e a taxa de juros americana exerceram influência positiva na taxa de câmbio. Elevação na taxa de juros americana e na taxa de câmbio esperada elevam o rendimento dos títulos denominados em dólar, o que reduz a demanda de títulos em reais e aumenta a demanda de dólares, desvalorizando, assim, a moeda brasileira.

Embora significativos e coerentes com a teoria, a demanda e a oferta de moeda apresentaram coeficientes próximos de zero, o que mostra que tais variáveis têm pequena influência na determinação da taxa de câmbio.

O modelo que continha o IPA americano é apresentado na Tabela 2. Assim como no modelo anterior, os sinais das variáveis significativas estatisticamente foram coerentes com a teoria econômica. A variável IPA americano, inserida neste modelo para tentar captar a tendência de aumento do déficit público americano que é financiado pelo aumento da oferta de moeda, não foi significativa a $10 \%$, embora seu sinal esteja coerente com o especificado. Isso mostra que aumento na oferta monetária americana para atender ao seu déficit fiscal não foi importante para determinar a taxa de câmbio real/dólar.

Tabela 2 - Equação de co-integração, estimada a partir de um modelo VAR para taxa de câmbio nominal, representado na forma de um modelo de correção de erros vetorial

\begin{tabular}{|c|c|c|c|c|c|c|c|c|}
\hline Câmbio & IGP-DI & IPA_EUA & $\begin{array}{l}\text { Demanda } \\
\text { de moeda }\end{array}$ & $\begin{array}{c}\text { Oferta de } \\
\text { moeda }\end{array}$ & $\begin{array}{l}\text { Taxa de } \\
\text { câmbio } \\
\text { esperada }\end{array}$ & $\begin{array}{c}\text { Taxa de } \\
\text { juros } \\
\text { americana }\end{array}$ & Renda & $\begin{array}{c}\text { Taxa de } \\
\text { juros } \\
\text { nacional }\end{array}$ \\
\hline 1 & $\begin{array}{c}-0,017^{*} \\
(0,00608) \\
{[2,86858]}\end{array}$ & $\begin{array}{c}-0,007^{\text {ns }} \\
(0,00477) \\
{[1,37609]}\end{array}$ & $\begin{array}{c}-2,29 \mathrm{E}- \\
05^{*} \\
(4,0 \mathrm{E}-06) \\
{[5,24978]}\end{array}$ & $\begin{array}{c}4,84 \mathrm{E}-05^{*} \\
(8 \mathrm{E}-06) \\
{[-6,304]}\end{array}$ & $\begin{array}{c}1,832^{\circ} \\
(0,08335) \\
{[-} \\
21,9744]\end{array}$ & $\begin{array}{c}0,072^{*} \\
(0,02166) \\
{[3,33692]}\end{array}$ & $\begin{array}{c}-6,34 \mathrm{E}- \\
05^{*} \\
(1,4 \mathrm{E}-05) \\
{[4,60850]}\end{array}$ & $\begin{array}{c}-0,055^{*} \\
(0,00389) \\
{[14,2593]}\end{array}$ \\
\hline
\end{tabular}

Fonte: dados do trabalho.

OBS: Os valores entre parênteses correspondem ao desvio-padrão e os valores em colchete, ao t-valor.

ns- não-significativo.

*-significativo a $1 \%$. 
As demais variáveis apresentaram resultados semelhantes aos do modelo anterior e podem ser interpretadas de forma similar. Confirmando o que Takami e Leme (2003) haviam indicado, o mercado monetário é de suma importância para explicar choques na taxa de câmbio. Isso fica mais claro quando se analisa, adiante, o poder de previsão dos modelos. Além disso, pode-se perceber a importância das variáveis reais (representada no modelo pela renda) e nominais na determinação da taxa de câmbio.

\subsection{Previsões para taxa de câmbio real/dólar}

Foram estimadas taxas de câmbio para o período de janeiro de 2005 a dezembro de 2005. No período de janeiro de 2005 a maio de 2005, os valores para a taxa de câmbio já eram conhecidos e serviram para testar o poder de previsão do modelo. Para estimar a taxa de câmbio foi utilizada a técnica pela qual se incorporam os valores previstos, para um período futuro (para todas as variáveis), na amostra e novamente se estima o modelo. Esta técnica é conhecida por previsão um passo a frente.

Para cada uma das relações apresentadas no item anterior foram estimados MCEV. Como a variável de interesse para a realização de previsões é a taxa de câmbio, foram elaborados MCEV para essa variável, em ambos os modelos. As previsões para o modelo sem o IPA americano são apresentadas na equação (4) e as previsões com o IPA americano, na equação (5).

$$
\Delta C=i u_{t-1}+j \Delta I G P_{t-1}+l \Delta I P A_{t-1}^{E U A}+m \Delta L_{t-1}+n \Delta M_{t-1}^{s}+o \Delta E_{t-1}^{e}+p \Delta R_{t-1}^{E U A}+q \Delta R_{t-1}^{B R A}+r \Delta Y_{t-1} .
$$


No primeiro modelo, os valores preditos e observados para taxa de câmbio e erro de previsão do modelo, nos cinco primeiros meses de 2005, encontram-se na Tabela 3.

Tabela 3 - Poder de previsão da taxa de câmbio do modelo sem o IPA americano

\begin{tabular}{lccc}
\hline \multicolumn{1}{c}{ Período } & $\begin{array}{c}\text { Valor observado da taxa } \\
\text { de câmbio (comercial }- \\
\text { compra-fim de período) }\end{array}$ & $\begin{array}{c}\text { Previsão para taxa } \\
\text { de câmbio }\end{array}$ & Erro (\%) \\
\hline Janeiro/2005 & 2.624 & 2.6175 & -0.24771 \\
Fevereiro/2005 & 2.5942 & 2.6792 & 3.27654 \\
Março/2005 & 2.6654 & 2.6275 & -1.42193 \\
Abril/2005 & 2.5305 & 2.5203 & -0.40308 \\
Maio/2005 & 2.403 & 2.5464 & 5.967541 \\
\hline
\end{tabular}

Fonte: Dados do trabalho.

A Tabela 4 mostra as previsões para a taxa de câmbio, nos cinco primeiros meses de 2005, considerando a inclusão do IPA americano no modelo.

Como se pode observar, ambos os modelos apresentaram erros de previsão satisfatórios (menores do que 10\%, principalmente por se tratar de uma variável tão volátil; no primeiro caso, inferior a $6 \%$ e, no segundo, inferior a 5\%), contudo, o modelo com o IPA americano parece apresentar erro de previsão menor, visto que o período de previsão se estende, ao contrário do que ocorre no primeiro modelo, embora o IPA americano não tenha sido significativo individualmente para explicar a taxa de câmbio nominal no longo prazo. 
Tabela 4 - Poder de previsão da taxa de câmbio no modelo com o IPA americano

\begin{tabular}{lccc}
\hline \multicolumn{1}{c}{ Período } & $\begin{array}{c}\text { Valor observado da taxa de } \\
\text { câmbio (comercial-compra- } \\
\text { fim de período) }\end{array}$ & $\begin{array}{c}\text { Previsão para } \\
\text { taxa de câmbio }\end{array}$ & Erro (\%) \\
\hline Janeiro/2005 & 2.624 & 2.6346 & 0.403963 \\
Fevereiro/2005 & 2.5942 & 2.674 & 3.076093 \\
Março/2005 & 2.6654 & 2.6044 & -2.28859 \\
Abril/2005 & 2.5305 & 2.4913 & -1.5491 \\
Maio/2005 & 2.403 & 2.5031 & 4.165626 \\
\hline
\end{tabular}

Fonte: Dados do trabalho.

A Figura 2 apresenta o comportamento das séries de câmbio, previsto e observado. Percebe-se que as séries previstas tiveram comportamento semelhante aos valores observados, sempre com tendência de queda. Vale destacar a precisão das previsões nos períodos de janeiro, março e abril de 2005.

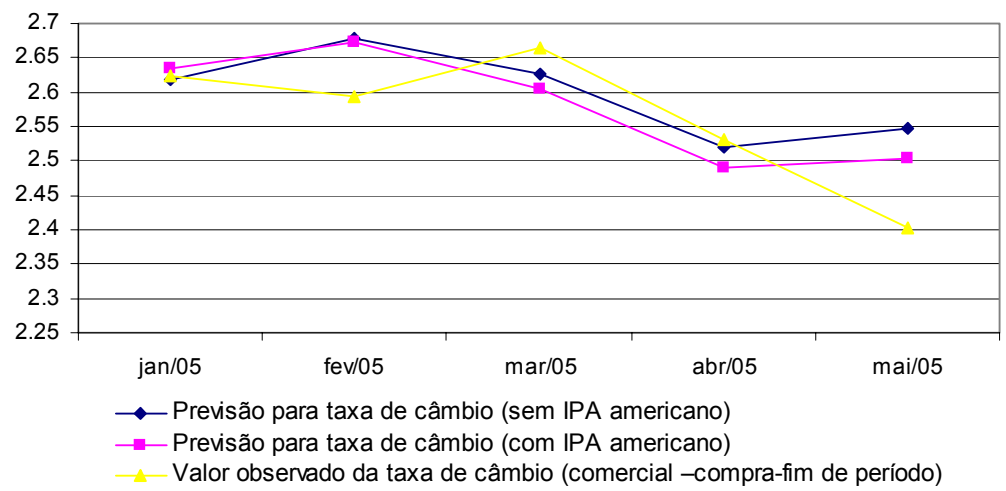

Fonte: Dados do trabalho.

Figura 2 - Comportamento das séries, previsto e observado, para a taxa nominal de câmbio. 
A Tabela 5 apresenta as previsões para a taxa de câmbio nos meses de junho de 2005 a dezembro de 2005, por ambos os modelos.

Tabela 5 - Previsão do câmbio (comercial - compra fim de período), nos meses de junho a dezembro de 2005

\begin{tabular}{lcc}
\hline \multicolumn{1}{c}{ Período } & $\begin{array}{c}\text { Previsão da taxa de câmbio no } \\
\text { modelo sem o IPA americano }\end{array}$ & $\begin{array}{c}\text { Previsão da taxa de câmbio no } \\
\text { modelo com o IPA americano }\end{array}$ \\
\hline Junho/2005 & 2.5089 & 2.4559 \\
Julho/2005 & 2.4964 & 2.4478 \\
Agosto/2005 & 2.4955 & 2.4478 \\
Setembro/2005 & 2.4711 & 2.4244 \\
Outubro/2005 & 2.4888 & 2.4474 \\
Novembro/2005 & 2.4879 & 2.4532 \\
Dezembro/2005 & 2.4873 & 2.4569 \\
\hline
\end{tabular}

Fonte: Dados do trabalho.

De acordo com ambos os modelos, há tendência de leve queda na taxa de câmbio até o final do ano, que fechará em dezembro, no caso do modelo sem o IPA americano, em R $\$ 2,4873$ e no modelo contendo o IPA americano, em R\$ 2,4569 por dólar. Este resultado mostra que aumento na oferta de moeda por parte do governo americano para financiar o déficit, embora não apresente relação de longo prazo com o câmbio real/dólar, pode influenciar a moeda brasileira no curto prazo.

Ambos os modelos apresentaram bom poder de previsão, o que mostra que a teoria da determinação da taxa de câmbio por meio da paridade da taxa de juros, atrelada à análise do mercado monetário, é apropriada quando o objetivo é predizer valores para a taxa de câmbio. Além disso, os resultados foram coerentes com a tendência esperada pelo mercado, que é a de estabilidade da taxa de câmbio, com leve viés de queda. 


\section{Conclusão}

O trabalho mostrou que variáveis nominais são de suma importância para determinar a taxa de câmbio nominal, além das variáveis reais. Além disso, conclui-se que o modelo de paridade da taxa de juros, atrelado ao mercado monetário, é consistente para o caso brasileiro no período de análise.

Por meio de Modelos de Correção de Erros Vetorial verificou-se que as variáveis oferta de moeda, demanda de moeda e renda são significativas estatisticamente para explicar mudanças na taxa de câmbio, porém apresentam coeficientes muito próximos de zero, em ambos os modelos estimados. As demais variáveis, com exceção do IPA americano, exerceram influência, do ponto de vista estatístico, na taxa de câmbio, e tais influências foram coerentes com a teoria utilizada. A taxa de juros nacional afetou positivamente a taxa de câmbio, ao passo que a taxa de juros americana, a taxa de câmbio esperada e o índice de preços brasileiro a afetaram negativamente.

De acordo com as previsões, ambos os modelos apresentaram bom poder preditivo, o que sinaliza tendência de queda na taxa de câmbio. $O$ câmbio fecharia o mês de dezembro de 2005, de acordo com o modelo com o IPA americano, em R \$ 2,45 por dólar. Ao se confirmar essa previsão, poder-se-ia observar crescimento nos investimentos em títulos denominados em reais, provocando uma expansão no fluxo de capitais do país. Com relação à balança comercial, poder-se-ia esperar redução nos superávits observados nos últimos meses.

Contudo, essa tendência de queda na taxa de câmbio pode ser conveniente para o governo, com vistas no controle da inflação. Embora não esteja apresentada na discussão dos resultados, a previsão para o IGP-DI está colocada no Apêndice (Tabela 6A) e apresenta tendência de queda. Este, talvez, seja o motivo de o governo não estar tentando evitar essa queda na taxa de câmbio. 


\section{Referência bibliográficas}

BACEN. Análise do Mercado de Câmbio. Brasília. $1^{\circ}$ trimestre de 1999. Disponível em <www.bcb.gov.br> . Acesso em 25/04/2005.

BACEN(a). Análise do Mercado de Câmbio. Brasília. $2^{\circ}$ trimestre de 2003. Disponível em <www.bcb.gov.br> . Acesso em 25/04/2005.

BACEN(b). Análise do Mercado de Câmbio. Brasília. $3^{\circ}$ trimestre de 2003. Disponível em <www.bcb.gov.br> . Acesso em 25/04/2005.

BACEN(c). Análise do Mercado de Câmbio. Brasília. $4^{\circ}$ trimestre de 2003. Disponível em <www.bcb.gov.br> . Acesso em 25/04/2005.

BARBOSA, C.P.M. Fatores e Políticos e Institucionais: Impactos Sobre Paradas Bruscas de Financiamento Externo. Julho de 2004. Disponível em <www.puc-rio.br> . Acesso em 11/07/2005.

BLANCHARD, O. Macroeconomia: Teoria e Política Econômica. Rio de Janeiro: Editora Campus, 1999. 622p.

BRAGA, A. Determinantes da Taxa de Câmbio Real, Teoria e Evidências Empíricas: Uma Aplicação Para o Brasil. Economia Aplicada. São Paulo. V. 9, n. 1, p. 77-102, jan./mar. 2005.

FEDERAL RESERVE BOARD - FED. Disponível em $<$ www.federealreserve.gov> 2005.

GONDIM, J.L.B. e DOMINGUES, E.P. Modelando o Câmbio Após a Estabilização. 2003. Disponível em <www.anpec.org.br/encontro2003/ artigos/c48.pdf> . Acesso em 11/07/2005.

HOLANDA, M.C. e CAVALCANTE, M.T. Mobilidade de Capital Internacional no Brasil. Fortaleza. Universidade Federal do Ceará, CAEN. 1997. Disponível em <www.caen.efc.br> . Acesso em 11/07/ 2005. 
INSTITUTO DE PESQUISA ECONÔMICA APLICADA - IPEA. Disponível em: <www.ipea.gov.br>.

KANNEBLEY JUNIOR, S. e PAZELLO, E.T. Choques Nominais e Reais na Taxa de Câmbio: Evidência Empírica para o Brasil pós Desvalorização de 1999. 2003. Disponível em <www.anpec.org.br/ encontro2003/artigos/c48.pdf> . Acesso em 11/07/2005.

KRUGMAN, P.R., OBSTFELD, M. Economia internacional: teoria e política. São Paulo: Makron Books, 2005, 558 p.

MAIA, S.F. e RAMALHO, H.M.B. Efeitos da Reais e Nominais Sobre as Flutuações da Taxa Real de Câmbio Brasil/Estados Unidos: Um Estudo Empírico Usando VAR (1999-2003). 2003. Disponível em <www.anpec.org.br/encontro2003/artigos/c48.pdf> . Acesso em 11/07/2005.

ROGOFF, K. The Purchasing Power Parity Puzzle. In: Journal of Economic Literature XXIV. 1996.

SCHMIDT, C.A.J. e LIMA, M.A.M. A Demanda por Energia Elétrica no Brasil. Revista Brasileira de Economia. Rio de Janeiro. V.58, n.1, p 67-98, jan./mar. 2004.

TAKAMI, M.Y. e LEME, M.C. da S. Estudo das Relações da Paridade de Juros para a Economia Brasileiro no Período do Recente. 2003. Disponível em <www.anpec.org.br/encontro2003/ artigos/c48.pdf> . Acesso em 11/07/2005. 
Abstract - The present work looked for to show the influence of nominal variable in the determination of nominal exchange rate R $\$ / U S S$. For this, the model of the parity of the tax of interests was used, ally to the monetary market. It was looked, also, to foresee the tax of exchange rate R \$/USS, until December of 2005. For reaching such objectives, the equations of the system had been obtained by the Vector Error Correction Model (VECM). The results had shown that the nominal variable are very important to determinate the exchange rate and that the model of parity of the tax of interests, ally to the monetary market is confirmed for the Brazilian case in the period of analysis (jan/ 1999 to dez/2004). This conclusion is made on the basis of the high capacity of forecast of the model structuralized for the development of the study. Admitting the forecasted values, the exchange rate presents a light trend of fall until December of 2005, closing in $2,45 \mathrm{R} \$ / \mathrm{US} \$$.

Key-words: exchange, forecast, Brazil. 


\section{Anexo A}

Tabela 1A - Teste do Multiplicador de Lagrange (LM) para detectar auto-correlação nos modelos estimados

\begin{tabular}{ccccc}
\hline & $\begin{array}{c}\text { Modelo para previsão de câmbio } \\
\text { sem IPA americano }\end{array}$ & \multicolumn{2}{c}{$\begin{array}{c}\text { Modelo para previsão de câmbio } \\
\text { com IPA americano }\end{array}$} \\
\hline Lags & Estatística LM & Probabilidade & Estatística LM & Probabilidade \\
1 & 46,56684 & 0,5723 & 61,20440 & 0,5760 \\
2 & 45,38469 & 0,6205 & 69,61926 & 0,29 \\
\hline
\end{tabular}

Fonte: Dados do trabalho.

Tabela 2A - Resultado do teste Phillips - Perron (PP), que testa a estacionariedade

\begin{tabular}{cccc}
\hline Variável & PP & Variável em $1^{\text {a diferença }}$ & PP \\
\hline Câmbio & $-2,03374^{\text {ns }}$ & Câmbio & $-9,980835^{*}$ \\
IGP-DI & $-1,772689^{\text {ns }}$ & IGP-DI & $-3,667290^{* *}$ \\
IPA $_{\text {EUA }}$ & $-1,189608^{\text {ns }}$ & IPA A & $-7,738919^{*}$ \\
Demanda de moeda & $-3,773387^{* *}$ & Demanda de moeda & $-10,13847^{*}$ \\
Oferta de moeda & $-2,307595^{\text {ns }}$ & Oferta de moeda & $-6,826365^{*}$ \\
Câmbio estimado & $-2,098836^{\text {ns }}$ & Câmbio estimado & $-8,645714^{*}$ \\
Taxa de juros americana & $-1,415743^{\text {ns }}$ & Taxa de juros americana & $-3,115091^{* *}$ \\
Renda & $-4,751461^{*}$ & Renda & $-12,25516^{*}$ \\
Taxa de juros nacional & $-3,041296^{\text {ns }}$ & Taxa de juros nacional & $-11,21457^{*}$ \\
\hline
\end{tabular}

Fonte: Dados do trabalho.

Tabela 3A - Teste de Johansen para co-integração

\begin{tabular}{cccc}
\hline \multirow{2}{*}{ Modelo Estimado } & & \multicolumn{2}{c}{ Teste traço de Johansen } \\
Valor & $\begin{array}{c}\text { Valor crítico (5\% } \\
\text { observado }\end{array}$ & de significância) \\
\hline \multirow{3}{*}{$\begin{array}{c}\text { Modelo para previsão de } \\
\text { câmbio sem IPA americano }\end{array}$} & $\mathrm{R}=0$ & 199.29 & 169.41 \\
& $\mathrm{R}=1$ & 138.74 & 134.54 \\
& $\mathrm{R}=2$ & 91.19 & 103.68 \\
\cline { 2 - 4 } Modelo para previsão de & $\mathrm{R}=0$ & 59.51 & 76.81 \\
câmbio com IPA americano & $\mathrm{R}=1$ & 280.48 & 208.27 \\
& $\mathrm{R}=2$ & 150.95 & 169.41 \\
& $\mathrm{R}=3$ & 102.16 & 134.54 \\
\hline
\end{tabular}

Fonte: Dados do trabalho. 
Tabela 4A - Teste de White para detectar heterocedasticidade nos modelos estimados

\begin{tabular}{cccc}
\hline \multicolumn{2}{c}{$\begin{array}{c}\text { Modelo para previsão de } \\
\text { câmbio sem IPA americano }\end{array}$} & \multicolumn{2}{c}{$\begin{array}{c}\text { Modelo para previsão de câmbio com } \\
\text { IPA americano }\end{array}$} \\
\hline$\chi^{2}$ & Probabilidade & $\chi^{2}$ & Probabilidade \\
833,0483 & 0,5611 & 1198,938 & 0,6902 \\
\hline
\end{tabular}

Fonte: Dados do trabalho.

Tabela 5A - Teste de Akaike (AIC), Schwartz (SBC) e Hannan-Quinn (HQ) para determinar o número de defasagens dos modelos

\begin{tabular}{ccccc}
\hline Modelo Estimado & Lags & AIC & SBC & HQ \\
\hline & 1 & 57.77216 & $59.63005^{*}$ & 58.50630 \\
Modelo para & 2 & 56.43189 & 59.91544 & $57.80841^{*}$ \\
previsão de & 3 & 56.00882 & 61.11801 & 58.02771 \\
câmbio sem IPA & 4 & 56.04051 & 62.77536 & 58.70177 \\
americano & 5 & 55.21656 & 63.57706 & 58.52019 \\
& 6 & $54.17350^{*}$ & 64.15965 & 58.11950 \\
\cline { 2 - 5 } & 1 & 59.61129 & $62.00001^{*}$ & 60.55519 \\
Modelo para & 2 & 58.38489 & 62.89691 & 60.16781 \\
previsão de & 3 & 57.54936 & 64.18468 & 60.17129 \\
câmbio com IPA & 4 & 57.46139 & 66.22001 & 60.92233 \\
americano & 5 & 56.33401 & 67.21593 & 60.63398 \\
& 6 & $52.70546^{*}$ & 65.71068 & $57.84444 *$ \\
\hline
\end{tabular}

Fonte: Dados do trabalho. 
Tabela 6A - Previsão para o IGP-DI (Base dezembro de 2004) para os meses de janeiro a dezembro de 2005

\begin{tabular}{lcc}
\hline \multicolumn{1}{c}{ Período } & $\begin{array}{c}\text { Previsão para o IGP-DI no } \\
\text { modelo sem IPA americano }\end{array}$ & $\begin{array}{c}\text { Previsão para IGP-DI no } \\
\text { modelo com IPA americano }\end{array}$ \\
\hline Janeiro/2005 & 100.0841 & 100.1485 \\
Fevereiro/2005 & 100.229 & 100.2737 \\
Março/2005 & 100.4742 & 100.3873 \\
Abril/2005 & 100.6488 & 100.476 \\
Maio/2005 & 100.4791 & 100.1991 \\
Junho/2005 & 100.2696 & 99.8319 \\
Julho/2005 & 100.0996 & 99.5096 \\
Agosto/2005 & 99.8751 & 99.1867 \\
Setembro/2005 & 99.6955 & 98.9282 \\
Outubro/2005 & 99.5226 & 98.6745 \\
Novembro/2005 & 99.3472 & 98.484 \\
Dezembro/2005 & 99.2539 & 98.3741 \\
\hline
\end{tabular}

Fonte: Dados do trabalho. 
Tabela 7 A- Modelo de Correção de Erros Vetorial com IPA americano*

\begin{tabular}{|c|c|c|c|c|c|c|c|c|c|}
\hline Error Correction: & $\mathrm{D}(\mathrm{CAMBIO})$ & $\mathrm{D}\left(\mid \mathrm{GP} \_\mathrm{DI}\right)$ & D(IPA_EUA) & $\mathrm{D}(\mathrm{L})$ & $\mathrm{D}\left(\mathrm{M}^{\mathrm{s}}\right)$ & $\mathrm{D}\left(\mathrm{E}^{\mathrm{e}}\right)$ & $\mathrm{D}$ (Russ) & $\mathrm{D}$ (RENDA) & $D\left(R_{R \S}\right)$ \\
\hline CointEq1 & $\begin{array}{c}0.064598 \\
(0.09512) \\
{[0.67912]}\end{array}$ & $\begin{array}{c}0.097087 \\
(0.24745) \\
{[0.39236]}\end{array}$ & $\begin{array}{r}0.129217 \\
(0.47538) \\
{[0.27182]}\end{array}$ & $\begin{array}{c}2327.352 \\
(2788.92) \\
{[0.83450]}\end{array}$ & $\begin{array}{c}129.9084 \\
(1629.38) \\
{[0.07973]}\end{array}$ & $\begin{array}{c}0.064888 \\
(0.06319) \\
{[1.02691]}\end{array}$ & $\begin{array}{r}0.005970 \\
(0.08587) \\
{[0.06953]}\end{array}$ & $\begin{array}{r}878.9503 \\
(694.077) \\
{[1.26636]}\end{array}$ & $\begin{array}{r}-8.230063 \\
(0.84731) \\
{[-9.71313]}\end{array}$ \\
\hline $\mathrm{D}(\mathrm{CAMBIO}(-1))$ & $\begin{array}{r}-0.067028 \\
(0.35556) \\
{[-0.18851]}\end{array}$ & $\begin{array}{r}1.018459 \\
(0.92495) \\
{[1.10109]}\end{array}$ & $\begin{array}{c}0.254244 \\
(1.77699) \\
{[0.14308]}\end{array}$ & $\begin{array}{r}12442.56 \\
(10425.0) \\
{[1.19353]}\end{array}$ & $\begin{array}{r}5037.663 \\
(6090.63) \\
{[0.82712]}\end{array}$ & $\begin{array}{c}0.262102 \\
(0.23620) \\
{[1.10968]}\end{array}$ & $\begin{array}{c}-0.235557 \\
(0.32098) \\
{[-0.73388]}\end{array}$ & $\begin{array}{r}4169.709 \\
(2594.46) \\
{[1.60716]}\end{array}$ & $\begin{array}{r}3.431474 \\
(3.16726) \\
{[1.08342]}\end{array}$ \\
\hline $\mathrm{D}(\mathrm{CAMBIO}(-2))$ & $\begin{array}{c}0.300651 \\
(0.36771) \\
{[0.81763]}\end{array}$ & $\begin{array}{r}2.249320 \\
(0.95656) \\
{[2.35148]}\end{array}$ & $\begin{array}{r}1.470646 \\
(1.83771) \\
{[0.80026]}\end{array}$ & $\begin{array}{r}-1280.813 \\
(10781.2) \\
{[-0.11880]}\end{array}$ & $\begin{array}{r}-2559.130 \\
(6298.74) \\
{[-0.40629]}\end{array}$ & $\begin{array}{r}0.268359 \\
(0.24427) \\
{[1.09863]}\end{array}$ & $\begin{array}{r}-0.240819 \\
(0.33194) \\
{[-0.72548]}\end{array}$ & $\begin{array}{c}1613.644 \\
(2683.12) \\
{[0.60141]}\end{array}$ & $\begin{array}{r}-1.501668 \\
(3.27549) \\
{[-0.45846]}\end{array}$ \\
\hline $\mathrm{D}(\mathrm{IGP}$ _DI(-1)) & $\begin{array}{r}-0.069028 \\
(0.05016) \\
{[-1.37627]}\end{array}$ & $\begin{array}{r}0.725396 \\
(0.13047) \\
{[5.55966]}\end{array}$ & $\begin{array}{r}-0.025787 \\
(0.25066) \\
{[-0.10288]}\end{array}$ & $\begin{array}{r}3778.587 \\
(1470.56) \\
{[2.56948]}\end{array}$ & $\begin{array}{r}1251.508 \\
(859.153) \\
{[1.45668]}\end{array}$ & $\begin{array}{r}-0.017959 \\
(0.03332) \\
{[-0.53902]}\end{array}$ & $\begin{array}{r}0.019759 \\
(0.04528) \\
{[0.43640]}\end{array}$ & $\begin{array}{r}225.4171 \\
(365.979) \\
{[0.61593]}\end{array}$ & $\begin{array}{r}0.661896 \\
(0.44678) \\
{[1.48149]}\end{array}$ \\
\hline $\mathrm{D}\left(\mathrm{IGP} \_\mathrm{DI}(-2)\right)$ & $\begin{array}{c}0.039578 \\
(0.04820) \\
{[0.82120]}\end{array}$ & $\begin{array}{r}0.046185 \\
(0.12538) \\
{[0.36837]}\end{array}$ & $\begin{array}{c}0.302091 \\
(0.24087) \\
{[1.25418]}\end{array}$ & $\begin{array}{c}-2604.234 \\
(1413.09) \\
{[-1.84294]}\end{array}$ & $\begin{array}{r}-685.8178 \\
(825.574) \\
{[-0.83072]}\end{array}$ & $\begin{array}{c}0.005509 \\
(0.03202) \\
{[0.17208]}\end{array}$ & $\begin{array}{r}-0.017710 \\
(0.04351) \\
{[-0.40706]}\end{array}$ & $\begin{array}{r}-153.6462 \\
(351.675) \\
{[-0.43690]}\end{array}$ & $\begin{array}{r}-0.319658 \\
(0.42932) \\
{[-0.74457]}\end{array}$ \\
\hline$D\left(I P A \_E U A(-1)\right)$ & $\begin{array}{r}-0.025718 \\
(0.02812) \\
{[-0.91445]}\end{array}$ & $\begin{array}{r}0.069022 \\
(0.07316) \\
{[0.94341]}\end{array}$ & $\begin{array}{c}0.037408 \\
(0.14056) \\
{[0.26614]}\end{array}$ & $\begin{array}{r}-123.2763 \\
(824.601) \\
{[-0.14950]}\end{array}$ & $\begin{array}{c}228.3782 \\
(481.759) \\
{[0.47405]}\end{array}$ & $\begin{array}{r}-0.009866 \\
(0.01868) \\
{[-0.52807]}\end{array}$ & $\begin{array}{r}-0.044152 \\
(0.02539) \\
{[-1.73906]}\end{array}$ & $\begin{array}{c}114.1467 \\
(205.218) \\
{[0.55622]}\end{array}$ & $\begin{array}{r}-0.340362 \\
(0.25053) \\
{[-1.35859]}\end{array}$ \\
\hline $\mathrm{D}(\mathrm{IPA}$ _EUA $(-2))$ & $\begin{array}{c}0.020830 \\
(0.03039) \\
{[0.68546]}\end{array}$ & $\begin{array}{r}0.150088 \\
(0.07905) \\
{[1.89862]}\end{array}$ & $\begin{array}{r}-0.227664 \\
(0.15187) \\
{[-1.49906]}\end{array}$ & $\begin{array}{r}-137.5241 \\
(890.972) \\
{[-0.15435]}\end{array}$ & $\begin{array}{r}-118.9914 \\
(520.536) \\
{[-0.22859]}\end{array}$ & $\begin{array}{c}0.001109 \\
(0.02019) \\
{[0.05493]}\end{array}$ & $\begin{array}{r}0.058050 \\
(0.02743) \\
{[2.11614]}\end{array}$ & $\begin{array}{r}461.2130 \\
(221.736) \\
{[2.08001]}\end{array}$ & $\begin{array}{r}0.136832 \\
(0.27069) \\
{[0.50549]}\end{array}$ \\
\hline$D(L(-1))$ & $\begin{array}{c}1.31 \mathrm{E}-05 \\
(8.8 \mathrm{E}-06) \\
{[1.49956]}\end{array}$ & $\begin{array}{r}1.07 E-05 \\
(2.3 E-05) \\
{[0.47162]}\end{array}$ & $\begin{array}{c}7.07 \mathrm{E}-05 \\
(4.4 \mathrm{E}-05) \\
{[1.61495]}\end{array}$ & $\begin{array}{r}0.152420 \\
(0.25670) \\
{[0.59377]}\end{array}$ & $\begin{array}{r}0.404233 \\
(0.14997) \\
{[2.69541]}\end{array}$ & $\begin{array}{c}1.29 \mathrm{E}-05 \\
(5.8 \mathrm{E}-06) \\
{[2.20964]}\end{array}$ & $\begin{array}{r}-1.55 \mathrm{E}-06 \\
(7.9 \mathrm{E}-06) \\
{[-0.19610]}\end{array}$ & $\begin{array}{c}0.029142 \\
(0.06388) \\
{[0.45618]}\end{array}$ & $\begin{array}{r}0.000261 \\
(7.8 \mathrm{E}-05) \\
{[3.34736]}\end{array}$ \\
\hline$D(L(-2))$ & $\begin{array}{r}1.47 \mathrm{E}-05 \\
(8.9 \mathrm{E}-06) \\
{[1.65883]}\end{array}$ & $\begin{array}{r}2.61 \mathrm{E}-05 \\
(2.3 \mathrm{E}-05) \\
{[1.12842]}\end{array}$ & $\begin{array}{r}-1.56 \mathrm{E}-05 \\
(4.4 \mathrm{E}-05) \\
{[-0.35252]}\end{array}$ & $\begin{array}{c}0.217034 \\
(0.26027) \\
{[0.83386]}\end{array}$ & $\begin{array}{r}-0.022332 \\
(0.15206) \\
{[-0.14686]}\end{array}$ & $\begin{array}{c}7.31 \mathrm{E}-06 \\
(5.9 \mathrm{E}-06) \\
{[1.24023]}\end{array}$ & $\begin{array}{c}4.19 \mathrm{E}-06 \\
(8.0 \mathrm{E}-06) \\
{[0.52255]}\end{array}$ & $\begin{array}{r}0.003206 \\
(0.06477) \\
{[0.04950]}\end{array}$ & $\begin{array}{r}3.46 \mathrm{E}-05 \\
(7.9 \mathrm{E}-05) \\
{[0.43764]}\end{array}$ \\
\hline$D\left(M^{s}(-1)\right)$ & $\begin{array}{r}-3.28 \mathrm{E}-05 \\
(1.6 \mathrm{E}-05) \\
{[-2.05484]}\end{array}$ & $\begin{array}{r}-3.13 \mathrm{E}-05 \\
(4.2 \mathrm{E}-05) \\
{[-0.75423]}\end{array}$ & $\begin{array}{r}-5.14 \mathrm{E}-05 \\
(8.0 \mathrm{E}-05) \\
{[-0.64459]}\end{array}$ & $\begin{array}{r}-0.625855 \\
(0.46788) \\
{[-1.33764]}\end{array}$ & $\begin{array}{r}-0.273674 \\
(0.27335) \\
{[-1.00118]}\end{array}$ & $\begin{array}{r}-2.51 \mathrm{E}-05 \\
(1.1 \mathrm{E}-05) \\
{[-2.36651]}\end{array}$ & $\begin{array}{r}-3.37 \mathrm{E}-06 \\
(1.4 \mathrm{E}-05) \\
{[-0.23369]}\end{array}$ & $\begin{array}{r}-0.230267 \\
(0.11644) \\
{[-1.97753]}\end{array}$ & $\begin{array}{r}-0.000376 \\
(0.00014) \\
{[-2.64700]}\end{array}$ \\
\hline $\mathrm{D}\left(\mathrm{M}^{\mathrm{s}}(-2)\right)$ & $\begin{array}{c}5.01 \mathrm{E}-06 \\
(1.3 \mathrm{E}-05) \\
{[0.38069]}\end{array}$ & $\begin{array}{r}-5.02 E-06 \\
(3.4 E-05) \\
{[-0.14681]}\end{array}$ & $\begin{array}{r}0.000141 \\
(6.6 \mathrm{E}-05) \\
{[2.15308]}\end{array}$ & $\begin{array}{c}0.056123 \\
(0.38548) \\
{[0.14559]}\end{array}$ & $\begin{array}{c}0.197152 \\
(0.22521) \\
{[0.87540]}\end{array}$ & $\begin{array}{r}1.20 \mathrm{E}-05 \\
(8.7 \mathrm{E}-06) \\
{[1.37049]}\end{array}$ & $\begin{array}{c}3.49 \mathrm{E}-07 \\
(1.2 \mathrm{E}-05) \\
{[0.02941]}\end{array}$ & $\begin{array}{r}-0.052981 \\
(0.09594) \\
{[-0.55226]}\end{array}$ & $\begin{array}{r}-0.000198 \\
(0.00012) \\
{[-1.69122]}\end{array}$ \\
\hline $\mathrm{D}\left(\mathrm{E}^{\mathrm{e}}(-1)\right)$ & $\begin{array}{c}0.229515 \\
(0.51746) \\
{[0.44354]}\end{array}$ & $\begin{array}{r}0.806394 \\
(1.34612) \\
{[0.59905]}\end{array}$ & $\begin{array}{c}-0.184872 \\
(2.58612) \\
{[-0.07149]}\end{array}$ & $\begin{array}{r}-15737.18 \\
(15171.9) \\
{[-1.03726]}\end{array}$ & $\begin{array}{r}-6814.421 \\
(8863.91) \\
{[-0.76878]}\end{array}$ & $\begin{array}{r}-0.158270 \\
(0.34374) \\
{[-0.46043]}\end{array}$ & $\begin{array}{c}0.366596 \\
(0.46713) \\
{[0.78479]}\end{array}$ & $\begin{array}{c}1418.557 \\
(3775.82) \\
{[0.37570]}\end{array}$ & $\begin{array}{r}-3.114655 \\
(4.60943) \\
{[-0.67571]}\end{array}$ \\
\hline $\mathrm{D}\left(\mathrm{E}^{\mathrm{e}}(-2)\right)$ & $\begin{array}{r}0.136367 \\
(0.50103) \\
{[0.27217]}\end{array}$ & $\begin{array}{r}-1.075718 \\
(1.30338) \\
{[-0.82533]}\end{array}$ & $\begin{array}{r}-3.874495 \\
(2.50401) \\
{[-1.54731]}\end{array}$ & $\begin{array}{r}-6682.425 \\
(14690.2) \\
{[-0.45489]}\end{array}$ & $\begin{array}{r}-2098.801 \\
(8582.51) \\
{[-0.24454]}\end{array}$ & $\begin{array}{r}-0.038240 \\
(0.33283) \\
{[-0.11489]}\end{array}$ & $\begin{array}{r}-0.213301 \\
(0.45230) \\
{[-0.47160]}\end{array}$ & $\begin{array}{r}2428.162 \\
(3655.95) \\
{[0.66417]}\end{array}$ & $\begin{array}{r}2.761113 \\
(4.46310) \\
{[0.61865]}\end{array}$ \\
\hline$D\left(R^{\text {Uss }}(-1)\right)$ & $\begin{array}{c}0.021932 \\
(0.15318) \\
{[0.14318]}\end{array}$ & $\begin{array}{r}0.658693 \\
(0.39848) \\
{[1.65302]}\end{array}$ & $\begin{array}{r}1.571046 \\
(0.76554) \\
{[2.05220]}\end{array}$ & $\begin{array}{r}-867.9066 \\
(4491.19) \\
{[-0.19325]}\end{array}$ & $\begin{array}{r}-1336.064 \\
(2623.90) \\
{[-0.50919]}\end{array}$ & $\begin{array}{r}-0.002546 \\
(0.10176) \\
{[-0.02502]}\end{array}$ & $\begin{array}{c}0.800864 \\
(0.13828) \\
{[5.79164]}\end{array}$ & $\begin{array}{r}2104.202 \\
(1117.72) \\
{[1.88258]}\end{array}$ & $\begin{array}{r}0.883470 \\
(1.36449) \\
{[0.64747]}\end{array}$ \\
\hline$D\left(R^{\text {uss }}(-2)\right)$ & $\begin{array}{c}0.001890 \\
(0.16616) \\
{[0.01137]}\end{array}$ & $\begin{array}{r}-0.742224 \\
(0.43224) \\
{[-1.71715]}\end{array}$ & $\begin{array}{c}-0.039896 \\
(0.83041) \\
{[-0.04804]}\end{array}$ & $\begin{array}{c}-503.9326 \\
(4871.72) \\
{[-0.10344]}\end{array}$ & $\begin{array}{r}-33.78432 \\
(2846.22) \\
{[-0.01187]}\end{array}$ & $\begin{array}{c}0.000800 \\
(0.11038) \\
{[0.00725]}\end{array}$ & $\begin{array}{r}-0.061969 \\
(0.15000) \\
{[-0.41314]}\end{array}$ & $\begin{array}{r}-1356.446 \\
(1212.42) \\
{[-1.11879]}\end{array}$ & $\begin{array}{r}-0.680801 \\
(1.48010) \\
{[-0.45997]}\end{array}$ \\
\hline$D(Y(-1))$ & $\begin{array}{r}-4.51 \mathrm{E}-05 \\
(2.7 \mathrm{E}-05) \\
{[-1.64539]}\end{array}$ & $\begin{array}{r}-4.53 \mathrm{E}-05 \\
(7.1 \mathrm{E}-05) \\
{[-0.63597]}\end{array}$ & $\begin{array}{r}0.000179 \\
(0.00014) \\
{[1.30832]}\end{array}$ & $\begin{array}{c}0.127406 \\
(0.80344) \\
{[0.15858]}\end{array}$ & $\begin{array}{c}0.426551 \\
(0.46940) \\
{[0.90872]}\end{array}$ & $\begin{array}{r}-2.24 \mathrm{E}-05 \\
(1.8 \mathrm{E}-05) \\
{[-1.22853]}\end{array}$ & $\begin{array}{r}-7.26 \mathrm{E}-07 \\
(2.5 \mathrm{E}-05) \\
{[-0.02933]}\end{array}$ & $\begin{array}{r}-1.001240 \\
(0.19995) \\
{[-5.00741]}\end{array}$ & $\begin{array}{r}-0.000137 \\
(0.00024) \\
{[-0.55949]}\end{array}$ \\
\hline$D(Y(-2))$ & $\begin{array}{r}3.41 \mathrm{E}-05 \\
(2.4 \mathrm{E}-05) \\
{[1.44625]}\end{array}$ & $\begin{array}{r}-3.07 E-05 \\
(6.1 E-05) \\
{[-0.49998]}\end{array}$ & $\begin{array}{c}6.32 \mathrm{E}-05 \\
(0.00012) \\
{[0.53595]}\end{array}$ & $\begin{array}{r}1.742265 \\
(0.69151) \\
{[2.51949]}\end{array}$ & $\begin{array}{r}0.787205 \\
(0.40401) \\
{[1.94850]}\end{array}$ & $\begin{array}{r}4.25 \mathrm{E}-05 \\
(1.6 \mathrm{E}-05) \\
{[2.71530]}\end{array}$ & $\begin{array}{r}1.13 \mathrm{E}-05 \\
(2.1 \mathrm{E}-05) \\
{[0.53145]}\end{array}$ & $\begin{array}{r}-0.366728 \\
(0.17210) \\
{[-2.13094]}\end{array}$ & $\begin{array}{r}2.29 \mathrm{E}-05 \\
(0.00021) \\
{[0.10908]}\end{array}$ \\
\hline$D\left(R^{R \$}(-1)\right)$ & $\begin{array}{c}0.002392 \\
(0.00783) \\
{[0.30542]}\end{array}$ & $\begin{array}{r}-0.015799 \\
(0.02037) \\
{[-0.77564]}\end{array}$ & $\begin{array}{r}-0.029965 \\
(0.03913) \\
{[-0.76573]}\end{array}$ & $\begin{array}{c}-46.32122 \\
(229.581) \\
{[-0.20176]}\end{array}$ & $\begin{array}{r}-13.54887 \\
(134.129) \\
{[-0.10101]}\end{array}$ & $\begin{array}{c}0.002507 \\
(0.00520) \\
{[0.48194]}\end{array}$ & $\begin{array}{r}0.001789 \\
(0.00707) \\
{[0.25306]}\end{array}$ & $\begin{array}{r}22.23929 \\
(57.1356) \\
{[0.38924]}\end{array}$ & $\begin{array}{r}-0.073304 \\
(0.06975) \\
{[-1.05095]}\end{array}$ \\
\hline $\mathrm{D}\left(\mathrm{R}^{\mathrm{R} \$}(-2)\right)$ & $\begin{array}{r}-0.004326 \\
(0.00738) \\
{[-0.58605]}\end{array}$ & $\begin{array}{r}-0.003982 \\
(0.01920) \\
{[-0.20736]}\end{array}$ & $\begin{array}{r}-0.008950 \\
(0.03689) \\
{[-0.24261]}\end{array}$ & $\begin{array}{r}-213.3366 \\
(216.432) \\
{[-0.98570]}\end{array}$ & $\begin{array}{r}-99.81380 \\
(126.447) \\
{[-0.78937]}\end{array}$ & $\begin{array}{r}-0.005490 \\
(0.00490) \\
{[-1.11951]}\end{array}$ & $\begin{array}{c}-0.002657 \\
(0.00666) \\
{[-0.39871]}\end{array}$ & $\begin{array}{r}-14.78319 \\
(53.8633) \\
{[-0.27446]}\end{array}$ & $\begin{array}{r}-0.007099 \\
(0.06576) \\
{[-0.10796]}\end{array}$ \\
\hline
\end{tabular}

Fonte: Dados do trabalho.

* O valore entre parêntese é o erro-padrão e o valor entre colchete, estatística t. 
Tabela 8A- Modelo de Correção de Erros sem IPA americano*

\begin{tabular}{|c|c|c|c|c|c|c|c|c|}
\hline Error Correction: & $\mathrm{D}(\mathrm{CAMBIO})$ & D(IGP_DI) & $\mathrm{D}(\mathrm{L})$ & $\mathrm{D}\left(\mathrm{M}^{\mathrm{s}}\right)$ & $\mathrm{D}\left(\mathrm{E}^{\mathrm{e}}\right)$ & $\mathrm{D}$ (Russ) & $\mathrm{D}(\mathrm{Y})$ & $\mathrm{D}\left(\mathrm{R}_{\mathrm{R} \$}\right)$ \\
\hline CointEq1 & $\begin{array}{r}0.083708 \\
(0.08522) \\
{[0.98221]}\end{array}$ & $\begin{array}{l}0.212188 \\
(0.22855) \\
{[0.92841]}\end{array}$ & $\begin{array}{r}1049.538 \\
(2496.71) \\
{[0.42037]}\end{array}$ & $\begin{array}{r}-407.9786 \\
(1453.68) \\
{[-0.28065]}\end{array}$ & $\begin{array}{r}0.070505 \\
(0.05609) \\
{[1.25703]}\end{array}$ & $\begin{array}{r}-0.023770 \\
(0.08188) \\
{[-0.29029]}\end{array}$ & $\begin{array}{r}1355.481 \\
(627.649) \\
{[2.15962]}\end{array}$ & $\begin{array}{r}-7.497864 \\
(0.80237) \\
{[-9.34462]}\end{array}$ \\
\hline $\mathrm{D}(\mathrm{CAMBIO}(-1))$ & $\begin{array}{r}-0.086824 \\
(0.34734) \\
{[-0.24997]}\end{array}$ & $\begin{array}{l}0.615249 \\
(0.93148) \\
{[0.66051]}\end{array}$ & $\begin{array}{r}13363.12 \\
(10175.6) \\
{[1.31325]}\end{array}$ & $\begin{array}{r}5274.919 \\
(5924.63) \\
{[0.89034]}\end{array}$ & $\begin{array}{r}0.259671 \\
(0.22859) \\
{[1.13595]}\end{array}$ & $\begin{array}{r}-0.241553 \\
(0.33372) \\
{[-0.72382]}\end{array}$ & $\begin{array}{r}2884.233 \\
(2558.06) \\
{[1.12751]}\end{array}$ & $\begin{array}{r}4.387265 \\
(3.27016) \\
{[1.34161]}\end{array}$ \\
\hline $\mathrm{D}(\mathrm{CAMBIO}(-2))$ & $\begin{array}{c}0.154244 \\
(0.34666) \\
{[0.44495]}\end{array}$ & $\begin{array}{r}1.784782 \\
(0.92964) \\
{[1.91985]}\end{array}$ & $\begin{array}{r}-1001.773 \\
(10155.6) \\
{[-0.09864]}\end{array}$ & $\begin{array}{r}-1479.844 \\
(5912.95) \\
{[-0.25027]}\end{array}$ & $\begin{array}{r}0.226093 \\
(0.22814) \\
{[0.99101]}\end{array}$ & $\begin{array}{r}-0.509042 \\
(0.33306) \\
{[-1.52837]}\end{array}$ & $\begin{array}{r}-213.5092 \\
(2553.01) \\
{[-0.08363]}\end{array}$ & $\begin{array}{r}-0.844729 \\
(3.26372) \\
{[-0.25882]}\end{array}$ \\
\hline$D\left(I G P \_D I(-1)\right)$ & $\begin{array}{r}-0.065944 \\
(0.04890) \\
{[-1.34841]}\end{array}$ & $\begin{array}{r}0.761708 \\
(0.13115) \\
{[5.80788]}\end{array}$ & $\begin{array}{r}3606.330 \\
(1432.71) \\
{[2.51714]}\end{array}$ & $\begin{array}{r}1192.809 \\
(834.177) \\
{[1.42992]}\end{array}$ & $\begin{array}{r}-0.018598 \\
(0.03219) \\
{[-0.57782]}\end{array}$ & $\begin{array}{r}0.024608 \\
(0.04699) \\
{[0.52371]}\end{array}$ & $\begin{array}{r}335.6484 \\
(360.170) \\
{[0.93192]}\end{array}$ & $\begin{array}{l}0.846374 \\
(0.46043) \\
{[1.83821]}\end{array}$ \\
\hline$D\left(I G P \_D I(-2)\right)$ & $\begin{array}{l}0.027660 \\
(0.04726) \\
{[0.58523]}\end{array}$ & $\begin{array}{r}0.055991 \\
(0.12675) \\
{[0.44174]}\end{array}$ & $\begin{array}{r}-2523.704 \\
(1384.64) \\
{[-1.82264]}\end{array}$ & $\begin{array}{r}-541.0144 \\
(806.191) \\
{[-0.67108]}\end{array}$ & $\begin{array}{r}-0.000247 \\
(0.03111) \\
{[-0.00793]}\end{array}$ & $\begin{array}{r}-0.024837 \\
(0.04541) \\
{[-0.54694]}\end{array}$ & $\begin{array}{r}-189.4853 \\
(348.086) \\
{[-0.54436]}\end{array}$ & $\begin{array}{r}-0.306231 \\
(0.44499) \\
{[-0.68818]}\end{array}$ \\
\hline $\mathrm{D}(\mathrm{L}(-1))$ & $\begin{array}{r}1.41 \mathrm{E}-05 \\
(8.0 \mathrm{E}-06) \\
{[1.75329]}\end{array}$ & $\begin{array}{r}-7.06 E-06 \\
(2.2 E-05) \\
{[-0.32738]}\end{array}$ & $\begin{array}{r}0.204599 \\
(0.23542) \\
{[0.86906]}\end{array}$ & $\begin{array}{r}0.403204 \\
(0.13707) \\
{[2.94153]}\end{array}$ & $\begin{array}{r}1.32 E-05 \\
(5.3 E-06) \\
{[2.49656]}\end{array}$ & $\begin{array}{r}2.71 \mathrm{E}-06 \\
(7.7 \mathrm{E}-06) \\
{[0.35130]}\end{array}$ & $\begin{array}{r}-0.023927 \\
(0.05918) \\
{[-0.40428]}\end{array}$ & $\begin{array}{r}0.000327 \\
(7.6 \mathrm{E}-05) \\
{[4.32240]}\end{array}$ \\
\hline$D(L(-2))$ & $\begin{array}{c}1.03 E-05 \\
(7.9 \mathrm{E}-06) \\
{[1.29803]}\end{array}$ & $\begin{array}{r}4.74 \mathrm{E}-06 \\
(2.1 \mathrm{E}-05) \\
{[0.22319]}\end{array}$ & $\begin{array}{r}0.256053 \\
(0.23194) \\
{[1.10395]}\end{array}$ & $\begin{array}{r}0.015508 \\
(0.13505) \\
{[0.11484]}\end{array}$ & $\begin{array}{r}6.36 \mathrm{E}-06 \\
(5.2 \mathrm{E}-06) \\
{[1.21987]}\end{array}$ & $\begin{array}{r}-4.04 \mathrm{E}-06 \\
(7.6 \mathrm{E}-06) \\
{[-0.53146]}\end{array}$ & $\begin{array}{r}-0.071971 \\
(0.05831) \\
{[-1.23433]}\end{array}$ & $\begin{array}{r}2.66 \mathrm{E}-05 \\
(7.5 \mathrm{E}-05) \\
{[0.35699]}\end{array}$ \\
\hline $\mathrm{D}\left(\mathrm{M}^{\mathrm{s}}(-1)\right)$ & $\begin{array}{r}-3.13 E-05 \\
(1.5 E-05) \\
{[-2.05742]}\end{array}$ & $\begin{array}{r}-4.76 \mathrm{E}-06 \\
(4.1 \mathrm{E}-05) \\
{[-0.11641]}\end{array}$ & $\begin{array}{r}-0.706110 \\
(0.44631) \\
{[-1.58211]}\end{array}$ & $\begin{array}{r}-0.295992 \\
(0.25986) \\
{[-1.13906]}\end{array}$ & $\begin{array}{r}-2.52 \mathrm{E}-05 \\
(1.0 \mathrm{E}-05) \\
{[-2.51640]}\end{array}$ & $\begin{array}{r}-1.92 E-06 \\
(1.5 \mathrm{E}-05) \\
{[-0.13117]}\end{array}$ & $\begin{array}{r}-0.148093 \\
(0.11220) \\
{[-1.31993]}\end{array}$ & $\begin{array}{r}-0.000372 \\
(0.00014) \\
{[-2.59116]}\end{array}$ \\
\hline$D\left(M^{s}(-2)\right)$ & $\begin{array}{c}9.50 \mathrm{E}-06 \\
(1.2 \mathrm{E}-05) \\
{[0.77147]}\end{array}$ & $\begin{array}{c}6.95 \mathrm{E}-06 \\
(3.3 \mathrm{E}-05) \\
{[0.21032]}\end{array}$ & $\begin{array}{c}0.025243 \\
(0.36089) \\
{[0.06995]}\end{array}$ & $\begin{array}{c}0.156860 \\
(0.21012) \\
{[0.74652]}\end{array}$ & $\begin{array}{c}1.28 \mathrm{E}-05 \\
(8.1 \mathrm{E}-06) \\
{[1.57403]}\end{array}$ & $\begin{array}{r}1.01 \mathrm{E}-05 \\
(1.2 \mathrm{E}-05) \\
{[0.85139]}\end{array}$ & $\begin{array}{r}-0.008408 \\
(0.09072) \\
{[-0.09268]}\end{array}$ & $\begin{array}{r}-0.000113 \\
(0.00012) \\
{[-0.97827]}\end{array}$ \\
\hline$D\left(E^{e}(-1)\right)$ & $\begin{array}{c}0.206316 \\
(0.50506) \\
{[0.40850]}\end{array}$ & $\begin{array}{r}1.311855 \\
(1.35444) \\
{[0.96856]}\end{array}$ & $\begin{array}{r}-17550.12 \\
(14796.1) \\
{[-1.18613]}\end{array}$ & $\begin{array}{r}-6975.238 \\
(8614.82) \\
{[-0.80968]}\end{array}$ & $\begin{array}{r}-0.156487 \\
(0.33239) \\
{[-0.47079]}\end{array}$ & $\begin{array}{r}0.181531 \\
(0.48525) \\
{[0.37410]}\end{array}$ & $\begin{array}{r}3081.122 \\
(3719.59) \\
{[0.82835]}\end{array}$ & $\begin{array}{r}-6.065852 \\
(4.75504) \\
{[-1.27567]}\end{array}$ \\
\hline $\mathrm{D}\left(\mathrm{E}^{\mathrm{e}}(-2)\right)$ & $\begin{array}{r}0.341301 \\
(0.47993) \\
{[0.71115]}\end{array}$ & $\begin{array}{r}-0.204151 \\
(1.28705) \\
{[-0.15862]}\end{array}$ & $\begin{array}{r}-7818.672 \\
(14059.9) \\
{[-0.55610]}\end{array}$ & $\begin{array}{r}-3752.096 \\
(8186.20) \\
{[-0.45834]}\end{array}$ & $\begin{array}{r}0.025039 \\
(0.31585) \\
{[0.07927]}\end{array}$ & $\begin{array}{r}0.101287 \\
(0.46111) \\
{[0.21966]}\end{array}$ & $\begin{array}{r}5744.192 \\
(3534.53) \\
{[1.62517]}\end{array}$ & $\begin{array}{r}0.588501 \\
(4.51846) \\
{[0.13024]}\end{array}$ \\
\hline$D(\operatorname{Russ}(-1))$ & $\begin{array}{r}-0.029354 \\
(0.14277) \\
{[-0.20560]}\end{array}$ & $\begin{array}{r}0.536900 \\
(0.38289) \\
{[1.40224]}\end{array}$ & $\begin{array}{r}-1027.686 \\
(4182.70) \\
{[-0.24570]}\end{array}$ & $\begin{array}{r}-1032.592 \\
(2435.32) \\
{[-0.42401]}\end{array}$ & $\begin{array}{r}-0.014781 \\
(0.09396) \\
{[-0.15730]}\end{array}$ & $\begin{array}{r}0.680129 \\
(0.13718) \\
{[4.95808]}\end{array}$ & $\begin{array}{r}1632.638 \\
(1051.49) \\
{[1.55269]}\end{array}$ & $\begin{array}{r}0.748544 \\
(1.34420) \\
{[0.55687]}\end{array}$ \\
\hline $\mathrm{D}($ Russ $(-2))$ & $\begin{array}{r}0.023650 \\
(0.14377) \\
{[0.16450]}\end{array}$ & $\begin{array}{r}-0.302380 \\
(0.38556) \\
{[-0.78426]}\end{array}$ & $\begin{array}{r}-927.9539 \\
(4211.92) \\
{[-0.22032]}\end{array}$ & $\begin{array}{r}-52.63759 \\
(2452.33) \\
{[-0.02146]}\end{array}$ & $\begin{array}{r}-0.007229 \\
(0.09462) \\
{[-0.07640]}\end{array}$ & $\begin{array}{r}0.030276 \\
(0.13813) \\
{[0.21918]}\end{array}$ & $\begin{array}{r}-113.3878 \\
(1058.83) \\
{[-0.10709]}\end{array}$ & $\begin{array}{r}-0.808585 \\
(1.35359) \\
{[-0.59736]}\end{array}$ \\
\hline$D(Y(-1))$ & $\begin{array}{r}-3.97 \mathrm{E}-05 \\
(2.5 \mathrm{E}-05) \\
{[-1.58371]}\end{array}$ & $\begin{array}{r}-3.35 E-05 \\
(6.7 \mathrm{E}-05) \\
{[-0.49768]}\end{array}$ & $\begin{array}{r}0.279496 \\
(0.73455) \\
{[0.38050]}\end{array}$ & $\begin{array}{r}0.441570 \\
(0.42768) \\
{[1.03247]}\end{array}$ & $\begin{array}{r}-2.12 E-05 \\
(1.7 E-05) \\
{[-1.28743]}\end{array}$ & $\begin{array}{r}1.98 E-05 \\
(2.4 \mathrm{E}-05) \\
{[0.82035]}\end{array}$ & $\begin{array}{r}-0.964372 \\
(0.18466) \\
{[-5.22242]}\end{array}$ & $\begin{array}{r}-0.000222 \\
(0.00024) \\
{[-0.94245]}\end{array}$ \\
\hline$D(Y(-2))$ & $\begin{array}{c}3.34 \mathrm{E}-05 \\
(2.3 \mathrm{E}-05) \\
{[1.46820]}\end{array}$ & $\begin{array}{r}-4.75 E-05 \\
(6.1 \mathrm{E}-05) \\
{[-0.77980]}\end{array}$ & $\begin{array}{r}1.876159 \\
(0.66585) \\
{[2.81770]}\end{array}$ & $\begin{array}{r}0.827825 \\
(0.38768) \\
{[2.13533]}\end{array}$ & $\begin{array}{r}4.29 E-05 \\
(1.5 E-05) \\
{[2.86533]}\end{array}$ & $\begin{array}{r}1.41 \mathrm{E}-05 \\
(2.2 \mathrm{E}-05) \\
{[0.64608]}\end{array}$ & $\begin{array}{r}-0.421194 \\
(0.16739) \\
{[-2.51628]}\end{array}$ & $\begin{array}{r}-8.01 E-05 \\
(0.00021) \\
{[-0.37415]}\end{array}$ \\
\hline $\mathrm{D}\left(\mathrm{R}_{\mathrm{RS}}(-1)\right)$ & $\begin{array}{r}0.001926 \\
(0.00701) \\
{[0.27478]}\end{array}$ & $\begin{array}{r}-0.034208 \\
(0.01880) \\
{[-1.81939]}\end{array}$ & $\begin{array}{r}-14.86523 \\
(205.395) \\
{[-0.07237]}\end{array}$ & $\begin{array}{r}-12.16880 \\
(119.588) \\
{[-0.10176]}\end{array}$ & $\begin{array}{r}0.003055 \\
(0.00461) \\
{[0.66200]}\end{array}$ & $\begin{array}{r}-0.000927 \\
(0.00674) \\
{[-0.13769]}\end{array}$ & $\begin{array}{r}-28.36458 \\
(51.6342) \\
{[-0.54934]}\end{array}$ & $\begin{array}{r}-0.086123 \\
(0.06601) \\
{[-1.30473]}\end{array}$ \\
\hline $\mathrm{D}\left(\mathrm{R}_{\mathrm{RS}}(-2)\right)$ & $\begin{array}{r}-0.005087 \\
(0.00708) \\
{[-0.71830]}\end{array}$ & $\begin{array}{r}-0.013397 \\
(0.01899) \\
{[-0.70538]}\end{array}$ & $\begin{array}{r}-203.0977 \\
(207.475) \\
{[-0.97890]}\end{array}$ & $\begin{array}{r}-96.49469 \\
(120.800) \\
{[-0.79880]}\end{array}$ & $\begin{array}{r}-0.005397 \\
(0.00466) \\
{[-1.15802]}\end{array}$ & $\begin{array}{r}-0.005176 \\
(0.00680) \\
{[-0.76062]}\end{array}$ & $\begin{array}{r}-42.22373 \\
(52.1572) \\
{[-0.80955]}\end{array}$ & $\begin{array}{r}-0.010295 \\
(0.06668) \\
{[-0.15440]}\end{array}$ \\
\hline
\end{tabular}

Fonte: Dados do trabalho.

- $\mathrm{O}$ valore entre parêntese é o erro-padrão e o valor entre colchete, estatística t. 